\title{
Implementasi Google Pagerank untuk Menentukan Ranking Halaman Website
}

\author{
Etvin Trio Sagita ${ }^{1, *}$, Abd. Charis Fauzan ${ }^{2}$, Muhammad Holili $^{3}$, Binti Aulatul Mufida ${ }^{4}$, Muhammad \\ Asfa Ilhami ${ }^{5}$ \\ Program Studi Ilmu Komputer, Universitas Nahdlatul Ulama Blitar, Indonesia \\ ${ }^{1}$ etvinzeka@ gmail.com; ${ }^{2}$ abdcharis@ @unublitar.ac.id; ${ }^{3}$ holilimuhammad11@ gmail.com; ${ }^{4}$ bintiaula01@ gmail.com; \\ 5asfailhami123@gmail.com \\ * corresponding author
}

INFO ARTIKEL

\section{Sejarah Artikel}

Diterima: 10 Oktober 2019

Direvisi: 13 Desember 2020

Diterbitkan: 30 April 2020

Kata Kunci

Google Pagerank

Website

Perankingan

\begin{abstract}
ABSTRAK
Penelitian ini bertujuan untuk untuk megecek apakah halaman website memiliki sebuah otoritas atas isinya, jika halaman web semakin tinggi peringkatnya, maka kualitas dan otoritasnya lebih baik ketimbang halaman web lainnya. Ada banyak pemeriksa Google Pagerank yang tersedia di internet, sebagian besar metode rekayasa dan perhitungan yang digunakan adalah nilai yang sama yang menghasilkan perkiraan yang dekat dengan nilai aktual peringkat. Perhitungan ini akan menghitung hasil perhitungan persisten dan menghasilkan perhitungan Pagerank dan perhitungannya menggunakan aplikasi Microsoft Office Excel 2013. Pagerank mungkin merupakan cara yang baik untuk membantu dan mewakili halaman yang akan ditampilkan. Secara keseluruhan, percobaan kami dengan Pagerank menunjukkan bahwa struktur grafik Web sangat berguna untuk berbagai tugas pencarian informasi.
\end{abstract}

\section{PENDAHULUAN}

Pagerank adalah sebuah algoritma yang berfungsi menentukan situs laman mana yang lebih penting atau populer. Pagerank merupakan salah satu fitur utama mesin pencari google. Cara kerja Pagerank adalah sebuah situs akan semakin populer jika semakin banyak situs lain yang mengarah ke situsnya, dengan asumsi isi/content situs tersebut lebih berguna dari isi/content situs lain. Peringkat halaman dihitung dengan skala 1-10 [1]. Model yang mendasari Pagerank sangat terkait dengan indeks kutipan yang digunakan dalam literatur ilmiah untuk mengevaluasi pentingnya publikasi [2]. Pada penelitian kali ini Google Pagerank digunakan untuk megecek apakah halaman website memiliki sebuah otoritas atas isinya, jika halaman web semakin tinggi peringkatnya, maka kualitas dan otoritasnya lebih baik ketimbang halaman web lainnya [3]. Algoritma Pagerank ini menggunakan fungsi matematika yang kompleks berupa kombinasi antara perhitungan jumlah link yang mengarah pada suatu halaman web dengan analisis atau kualitas masing - masing link tersebut. Dengan menggunakan algoritma Pagerank dapat diketahui skala kepopuleran sebuah website [4].

Penelitian terdahulu tentang Pagerank pernah dilakukan Oleh Rima Aprilia[5] yang di implementasikan pada matlab untuk membentuk sebuah program dalam $m$-file yang berfungsi untuk membuka file dan mengkompilasi perintah-perintah didalamnya. Kemudian Oleh Yunius Nainggolan[6] yang di implementasikan pada aplikasi riset kanker sebagai alat bantu dalam peperangan melawa kanker. Kemudian pada penelitian selanjutnya Oleh Erwin Renaldhy dan Muhammad Rizal H [7] yang di implementasikan pada Pemrograman berorientasi objek (OOP). Namun pada penelitian ini kami implementasikan untuk menghitung halaman website menggunakan Microsoft Office Excel 2013 sebagai pembeda dari penelitian sebelumnya[8]. 
Berdasarkan latar belakang yang telah diuraikan maka penelitian ini berfokus untuk mengimplementasikan google Pagerank untuk merangking halaman website. Seperti yang kita ketahui bahwa Google adalah mesin pencari paling popular di dunia. Kita bisa mendapatkan begitu banyak informasi dan percaya pada hasil Google. Jadi, informasi itu informasi palsu, tipuan atau informasi salah, itu semua muncul di Google.

\section{METODE}

Metode penelitian terdiri dari beberapa tahap yaitu, pengambilan dan pengumpulan data. Yang di ranking adalah halaman website http://www.kitainformatika.com/2019/06/kriptografi-dokumen-word-docdocx.html?m=1. Website ini kami ranking untuk diketahui tingkat kepopuleran nya. Tahap pertama yang dilakukan yaitu pengambilan data dengan cara mengumpulkan data dari halaman website, kemudian dilakukan tahap filterisasi. Tahap kedua mengambildan dokumen dilakukan dengan mengumpulkan jurnal dari penelitian terdahulu untuk dijadikan referensi pada beberapa komponen yaitu judul, abstrak, peneliti dan referensi. Tahap ketiga pengimplementasian Google Pagerank menggunakan Microsoft Office Excel 2013. Tahap keempat pengujian dan evaluasi menggunakan rumus. Persamaan (1) adalah rumus algoritma Pagerank untuk melakukan perangkingan.

Keterangan:

$$
\mathrm{PR}(\mathrm{A})=((1-\mathrm{d})+\mathrm{d}(\mathrm{PR}(\mathrm{T} 1) / \mathrm{C}(\mathrm{T} 1)+\ldots+\mathrm{PR}(\mathrm{Tn}) / \mathrm{C}(\mathrm{Tn}))
$$

PR(A) : Pagerank halaman A

d : damping factor yang bisa diberi antara 0 dan 1

PR(T1) : nilai Pagerank halaman T1

C(T1) : jumlah link yang keluar dari halaman T1 berlaku seterusnya dari T2 sampai Tn [9].

Setelah semua Pagerank yang didapat dari halaman-halaman lain yang mengacu ke halaman "A" dijumlahkan, nilai itu kemudian dikalikan dengan damping factor yang bernilai antara 0 sampai 1 . Hal ini dilakukan agar tidak keseluruhan nilai Pagerank halaman T didistribusikan ke halaman A [10].

\section{HASIL DAN PEMBAHASAN}

Pada penelitian kali ini penulis menggunakan aplikasi Microsoft Office Excel untuk menerapkan perhitungan Pagerank. Di bagian ini penulis memberikan instruksi untuk menyiapkan spreadsheet Excel untuk menghitung Pagerank dengan sistem sebagai berikut.

\section{Langkah 1:}

Matriks hyperlink. Dalam spreadsheet Excel, masukkan matriks hyperlink A yang sesuai dengan Gambar 1. Jumlah baris telah dihitung dengan memasukkan rumus = SUM (B3: D3) di sel E3 dan kemudian menyeret ke sel E5.

\begin{tabular}{|c|c|c|c|c|c|c|}
\hline 4 & A & B & C & D & E & $\mathrm{F}$ \\
\hline 1 & Hyperlink & $\operatorname{trix} A$ & & & & \\
\hline 2 & & P1 & P2 & P3 & row sum & \\
\hline 3 & P1 & o & 1 & 0 & 1 & \\
\hline 4 & $\mathrm{P} 2$ & 1 & 0 & 1 & 2 & \\
\hline 5 & P3 & 1 & 0 & 0 & 1 & \\
\hline 6 & & & & & & \\
\hline
\end{tabular}

Gambar 1. hyperlink matrix A 


\section{Langkah 2:}

Sekarang mengatur spreadsheet untuk secara otomatis menghitung matriks Stochastic $\mathrm{S}$ dari matriks A seperti yang ditunjukkan Gambar 2, masukkan Rumusnya $=\mathrm{IF}(\$ \mathrm{E} 3=0,1 / 3$, B3/\$E3) di sel B9, dan kemudian drag Across dan down untuk membuat matriks 3x3. (Perhatikan penggunaan penting dari tanda $\$$ dalam rumus ini, untuk mencegah perubahan kolom ' E ' ketika diseret).

\begin{tabular}{|c|c|c|c|c|c|c|}
\hline$A$ & A & B & c & D & E & $\mathbf{F}$ \\
\hline 1 & \multicolumn{2}{|c|}{ Hyperlink matrix A } & & & & \\
\hline 2 & & P1 & P2 & P3 & row sum & \\
\hline 3 & P1 & $\mathrm{o}$ & 1 & o & 1 & \\
\hline 4 & P2 & 1 & o & 1 & 2 & \\
\hline 5 & P3 & 1 & o & o & 1 & \\
\hline \multicolumn{7}{|l|}{6} \\
\hline 7 & \multicolumn{2}{|c|}{ Stochastic matrix S } & & & & \\
\hline 8 & & P1 & P2 & P3 & & \\
\hline 9 & P1 & 0 & 1 & o & & \\
\hline 10 & P2 & 0.5 & 0 & 0.5 & & \\
\hline 11 & P3 & 1 & o & o & & \\
\hline 12 & & & & & & \\
\hline
\end{tabular}

\section{Langkah 3:}

Selanjutnya masukkan nilai 0,85 sebagai damping factor ke dalam sel B14. Seperti yang ditunjukkan pada Gambar 3, Setelah itu untuk membuat Google matriks masukkan rumus $=\$ \mathrm{~B} \$ 14 * \mathrm{~B} 9+(1-\$ \mathrm{~B} \$ 14) / 3$ di sel $\mathrm{B} 18$, lalu seret ke kiri dan kanan.

\begin{tabular}{|c|c|c|c|c|c|c|}
\hline 4 & A & B & c & D & E & $\mathrm{F}$ \\
\hline 1 & \multicolumn{2}{|c|}{ Hyperlink matrix A } & & & & \\
\hline 2 & & P1 & P2 & P3 & row sum & \\
\hline 3 & P1 & 0 & 1 & 0 & 1 & \\
\hline 4 & $\mathrm{P} 2$ & 1 & o & 1 & 2 & \\
\hline 5 & P3 & 1 & o & o & 1 & \\
\hline \multicolumn{7}{|l|}{6} \\
\hline 7 & \multicolumn{2}{|c|}{ Stochastic matrix S } & & & & \\
\hline 8 & & P1 & P2 & P3 & & \\
\hline 9 & P1 & 0 & 1 & 0 & & \\
\hline 10 & P2 & 0.5 & o & 0.5 & & \\
\hline 11 & P3 & 1 & o & 0 & & \\
\hline \multicolumn{7}{|l|}{12} \\
\hline 13 & \multicolumn{2}{|c|}{ Damping factor } & & & & \\
\hline 14 & $\mathrm{~d}=$ & 0.85 & & & & \\
\hline \multicolumn{7}{|l|}{15} \\
\hline 16 & \multicolumn{2}{|c|}{ Google matrix G } & & & & \\
\hline 17 & & P1 & $\mathrm{P} 2$ & P3 & & \\
\hline 18 & P1 & 0.05 & 0.9 & 0.05 & & \\
\hline 19 & P2 & 0.475 & 0.05 & 0.475 & & \\
\hline 20 & P3 & 0.9 & 0.05 & 0.05 & & \\
\hline 21 & & & & & & \\
\hline
\end{tabular}

Gambar 3. Damping factor dan google matrix G

Langkah 4:

Pada Iterasi pertama untuk memecahkan persamaan Pagerank v = vG. tambahkan dengan memasukkan hasil dari 1/3 dalam sel H4, I4, J4. Dalam melakukan perkalian matriks yang diperlukan untuk menghitung $\mathrm{v}^{(1)}, \mathrm{v}^{(2)}, \mathrm{v}^{(3)}, \ldots$, kita akan menggunakan formula array Excel. Pertama kita hitung vektor $\mathrm{v}^{(1)}=\mathrm{v}^{(0)} G$. blok kolom H5: J5, yang merupakan hasil dari 
perkalian matriks. Kemudian selanjutnya masukkan rumusnya =MMULT(H4:J4, \$B \$18:\$D \$20) dan tekan Control-Shift-Enter. Sehingga akan mendapatkan hasil $\mathrm{v}^{(1)}$ $=(0.475 .0 .333333 .0 .191667)$. seperti pada Gambar 4 berikut ini.

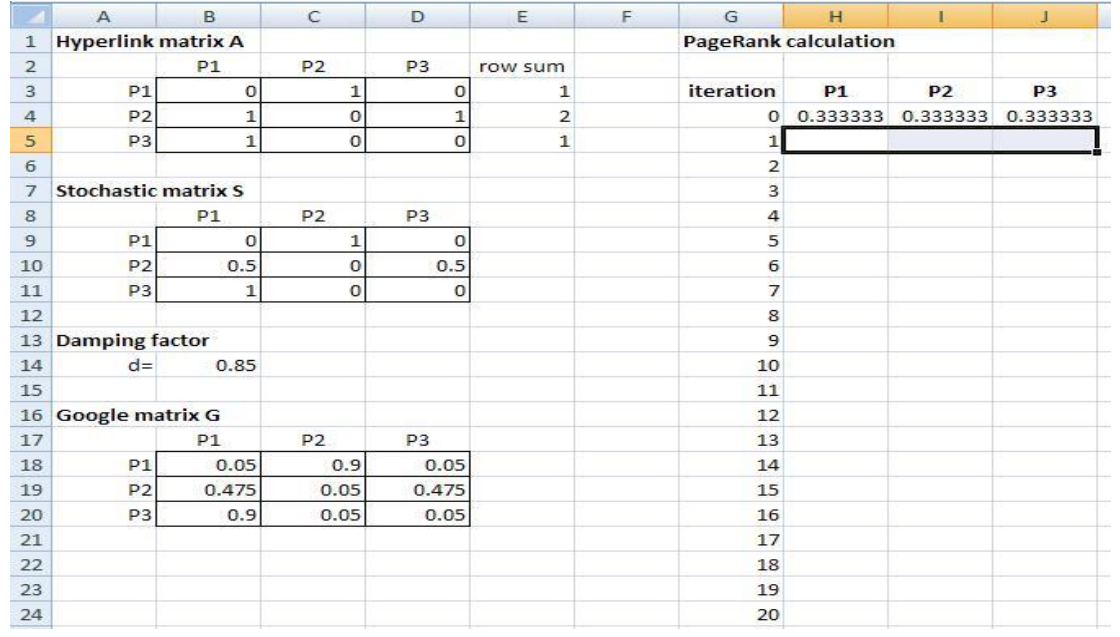

Gambar 4. hasil Iterasi pertama

Langkah 5:

Langkah terakhir blok kolom H5: J5 kemudian seret ke bawah untuk mendapatkan hasil iterasi yang sesuai. kemudian Spreadsheet harus sesuai pada gambar 5 berikut. Dari hasil penelitian tersebut telah ditemukan hasil Pageranks P1, P2 dan P3 adalah 0,397, 0,388 dan 0,215 .

\begin{tabular}{|c|c|c|c|c|c|c|c|c|c|c|}
\hline 4 & A & B & \multirow{3}{*}{$\begin{array}{l}\text { C } \\
\text { P2 }\end{array}$} & \multirow{3}{*}{$\begin{array}{l}\text { D } \\
\text { P3 }\end{array}$} & \multirow[t]{2}{*}{ E } & \multirow[t]{2}{*}{$\mathrm{F}$} & G & $\mathrm{H}$ & I & \multirow[t]{2}{*}{ J } \\
\hline 1 & \multicolumn{2}{|c|}{ Hyperlink matrix A } & & & & & \multicolumn{3}{|c|}{ PageRank calculation } & \\
\hline 2 & & P1 & & & row sum & & & & & \\
\hline 3 & $\mathrm{P} 1$ & 0 & 1 & 0 & 1 & & iteration & P1 & P2 & P3 \\
\hline 4 & P2 & 1 & 0 & 1 & 2 & & 0 & 0.333333 & 0.333333 & 0.333333 \\
\hline 5 & P3 & 1 & 이 & 0 & 1 & & 1 & 0.475 & 0.333333 & 0.191667 \\
\hline 6 & & & & & & & 2 & 0.354583 & 0.45375 & 0.191667 \\
\hline 7 & \multicolumn{2}{|c|}{ Stochastic matrix S } & & & & & 3 & 0.40576 & 0.351396 & 0.242844 \\
\hline 8 & & P1 & P2 & P3 & & & 4 & 0.40576 & 0.394896 & 0.199343 \\
\hline 9 & P1 & 0 & 1 & 0 & & & 5 & 0.387273 & 0.394896 & 0.217831 \\
\hline 10 & P2 & 0.5 & 0 & 0.5 & & & 6 & 0.402987 & 0.379182 & 0.217831 \\
\hline 11 & P3 & 1 & 0 & 0 & & & 7 & 0.396309 & 0.392539 & 0.211152 \\
\hline 12 & & & & & & & 8 & 0.396309 & 0.386862 & 0.216829 \\
\hline 13 & \multicolumn{2}{|c|}{ Damping factor } & & & & & 9 & 0.398721 & 0.386862 & 0.214416 \\
\hline 14 & $d=$ & 0.85 & & & & & 10 & 0.39667 & 0.388913 & 0.214416 \\
\hline 15 & & & & & & & 11 & 0.397542 & 0.38717 & 0.215288 \\
\hline 16 & \multicolumn{2}{|c|}{ Google matrix G } & & & & & 12 & 0.397542 & 0.387911 & 0.214547 \\
\hline 17 & & P1 & P2 & P3 & & & 13 & 0.397227 & 0.387911 & 0.214862 \\
\hline 18 & P1 & 0.05 & 0.9 & 0.05 & & & 14 & 0.397495 & 0.387643 & 0.214862 \\
\hline 19 & $\mathrm{P} 2$ & 0.475 & 0.05 & 0.475 & & & 15 & 0.397381 & 0.387871 & 0.214748 \\
\hline 20 & P3 & 0.9 & 0.05 & 0.05 & & & 16 & 0.397381 & 0.387774 & 0.214845 \\
\hline 21 & & & & & & & 17 & 0.397422 & 0.387774 & 0.214804 \\
\hline
\end{tabular}

Gambar 5. Hasil kalkulasi Pagerank

\section{KESIMPULAN}

Dengan menggunakan metode Pagerank ini peneliti dapat menyimpulkan bahwa hasil pencarian suatu Web yang lebih penting. Dalam percobaan, ini ternyata memberikan hasil pencarian berkualitas tinggi untuk pengguna. Pagerank juga dapat digunakan untuk memisahkan satu set kecil dokumen. penelitian telah menemukan bahwa Pageranks P1, P2 dan P3 adalah 0,397, 0,388 dan 0,215. Secara keseluruhan, percobaan peneliti dengan Pagerank menunjukkan bahwa struktur grafik Web sangat berguna untuk berbagai tugas 
pencarian informasi.Pengujian ini masih bersifat sederhana belum menggunakan data yang lebih besar.

\section{REFERENSI}

[1] lita karlitasari yani nuryani, sri styaningsih, "penerapan algoritma Pagerank untuk melihat tingkat kepopuleran website," penerapan Algoritm. Pagerank untuk melihat tingkat kepopuleran website, vol. 3, 2014.

[2] D. R. Andriyana, A. Komarudin, and R. Ilyas, "Visualisasi dan Pembobotan Jaringan Sitasi Makalah Ilmiah Dengan Algoritma Pagerank," pp. 325-327, 2019.

[3] R. Aprilia, "PENENTUAN RANKING SUATU WEB DENGAN ALGORITMA," 2009.

[4] M. Bianchini, M. Gori, and F. Scarselli, "Inside Pagerank," vol. 5, no. 1, pp. 92-128, 2005.

[5] R. Aprilia and R. F. Sari, "IMPLEMENTATION OF PAGERANK ALGORITHM IN MATLAB," vol. 1, no. 1, pp. 33-40, 2017.

[6] Y. Nainggolan, "Implementasi Breadth-First Search: Pagerank Algorithm dan Aplikasinya dalam Riset Kanker," 2013.

[7] E. Renaldhy and M. R. H, "IMPLEMENTASI ALGORITMA PAGERANK PADA PEMROGRAMAN BERORIENTASI OBJEK ( OOP ) ( Studi kasus Menggunakan Bahasa Pemrograman Java ),” pp. 108116.

[8] "Maths delivers! Google Pagerank."

[9] J. Oliver, “済無No Title No Title,” J. Chem. Inf. Model., vol. 53, no. 9, pp. 1689-1699, 2013.

[10] L. Choudhary and B. S. Burdak, "Role of Ranking Algorithms for Information Retrieval." 